\title{
La ley romana del talión y su base correlativa: antigüedad e innovación*
}

\author{
Benjamín García-Hernández \\ Universidad Autónoma de Madrid \\ benjamin.garciahernandez@uam.es \\ ORCID iD: http://orcid.org/0000-0003-0507-3930 \\ The Roman Law of Talion and its correlative origin: \\ antiquity and innovation
}

La ley del talión suele entenderse como un «ojo por ojo». Sin embargo, la norma romana dista de ser tan concreta y estricta como la del texto bíblico. Sin excluir la opción de membrum pro membro, la interpretación de los testimonios latinos se inclina por penas equiparables y no iguales, materialmente, al daño causado. El análisis lingüístico de talio, derivado del indefinido talis, y de la estructura correlativa (quale scelus, talis poena) en que surge, conduce a ver en ese sustantivo femenino de acción un neologismo de referencia proporcional que favoreció la evolución hacia penas sustitutorias menos cruentas. Para comprender el espíritu de la ley del talión, es necesario tener
The Law of Talion is usually understood as «an eye for an eye». However, Roman law is far from being as concise and strict as that of the Bible. Whilst not forgetting the option of membrum pro membro, the interpretation of Latin examples tells us that punishments tended to be comparable and not equal, materially speaking, to the harm caused. The linguistic analysis of talio, derived from the indefinite talis and the correlative structure (quale scelus, talis poena) in which it appears, leads us to see this feminine substantive of action as a neologism of proportional reference that encouraged Roman law to evolve towards substitute punishments that were less gory. In order to understand the spirit of the

* La idea sobre el origen «correlativo» de la palabra latina talio es fruto de las clases de Lenguaje Jurídico Romano que hemos impartido durante más de tres lustros en la Facultad de Derecho de la UAM, en coordinación con el Área de Derecho Romano, a cuyos profesores, en particular a E. Varela Mateos y A. Fernández de Buján, siempre estaremos agradecidos. El presente trabajo lo hemos realizado en el marco del proyecto de investigación Semántica latino-románica (Referencia: FFI2012-34826), subvencionado por el Ministerio de Economía y Competitividad. Una primera versión fue expuesta en la Tavola Rotonda Temi di lingua e di diritto romano a confronto dentro del 17th International Colloquium on Latin Linguistics, Università di Roma «Tor Vergata», 20-25 de mayo de 2013, y un año después en las XVII Jornadas de Filología Clásica sobre el tema El espíritu de las leyes: leyes y legisladores en el mundo antiguo, Universidad Autónoma de Madrid, 10-11 de abril de 2014. 
en cuenta su letra y esta consiste, ante todo, en el indefinido talis como correlativo de qualis referido al delito.
Law of Talion, we must take into consideration its form, which above all is made up of the indefinite talis as a correlative of qualis referring to the damage or harm caused.

Key words: talio; etymology; correlation; proportionality; crime; punishment.

Palabras clave: talio; etimología; correlación; proporcionalidad; delito; pena.

Benjamín 2017: «La ley romana del talión y su base Cómo citar este artículo / Citation: García-Hernández, Benjamín 2017 .
correlativa: antigüedad e innovación», Emerita 85 (2), pp. 223-239.

\section{El talión como pena compensatoria: membrum pro membro?}

La ley de las XII Tablas es, en el estado fragmentario en que se ha conservado, un gran depósito de arcaísmos, de prisca uerba. De ello se hace eco Cicerón en el Tratado de las leyes:

(1) Sunt certa legum uerba, Quinte, neque ita prisca ut in ueteribus XII sacratisque legibus ... (Cic., Leg. II 18).

Las palabras de las leyes, Quinto, son precisas, pero no tan arcaicas como en las viejas XII Tablas y en las Leyes sagradas ...

¿Será talio uno de esos notables arcaísmos del texto legal? Por las interpretaciones que refieren la palabra a la costumbre bárbara y cruel de despedazar partes del cuerpo humano como compensación de las dañadas por otro, así lo parece. Sin embargo, convendrá analizar junto con su contenido el origen de la expresión, por ver si esa interpretación se corresponde tal cual con el concepto fundamental.

La ley del talión, establecida a mediados del siglo $\mathrm{V}$ a. C. en las XII Tablas, es una ley arcaica, al menos desde el punto de vista cronológico. $\mathrm{Su}$ denominación ha tenido tal éxito que talión se llama ordinariamente a otras normas análogas, pero bastante más explícitas en la indicación de compensaciones miembro por miembro. Se trata de normas elementales y a la vez detallistas que prescriben castigos materialmente iguales al daño causado, como las que aparecen en diferentes formulaciones del Antiguo Testamento:

(2) Sin autem mors eius fuerit subsecuta reddet animam pro anima oculum pro oculo dentem pro dente manum pro manu pedem pro pede adustionem pro adustione uulnus pro uulnere liuorem pro liuore (Vulg., Exod. 21.23-25). 
Pero si se hubiera seguido su muerte, dará vida por vida, ojo por ojo, diente por diente, mano por mano, pie por pie, quemadura por quemadura, herida por herida, cardenal por cardenal.

En efecto, el «ojo por ojo» bíblico se ha llamado tradicionalmente ley del talión y esta aplicación, sin la menor salvedad, del nombre talión a la norma hebraica no ha beneficiado en absoluto la interpretación de la norma jurídica romana. Ahora bien, ¿era el talión exactamente un ojo por ojo, un miembro por miembro? Tal como está formulada la ley, no dejaba de serlo en una época en que las prácticas cruentas seguían en vigor. Pero en las XII Tablas no solo hay constancia de penas sustitutorias, menos crueles y más civilizadas, como la compensación económica, sino que, si nos atenemos al origen de la palabra, entenderemos que talio se limita a proponer penas equiparables al daño inferido.

La ley en cuestión, fijada en la tabla VIII, ha sido transmitida entre otros por el lexicógrafo Pompeyo Festo en un fragmento que le merece un breve comentario:

(3) Talionis mentionem fieri in XII $(8,2)$ ait Verrius hoc modo: «SI MEMBRVM RVP $<$ S $>$ IT, NI CVM EO PACIT, TALIO ESTO». Neque id quid significet, indicat, puto quia notum est; permittit enim lex parem uindictam (Fest., p. 496.15-19).

Afirma Verrio que en la Ley de las XII tablas (VIII 2) se hace mención del talión de este modo: «Si le rompiera un miembro y no hay pacto con él, se aplicará el talión». Y no indica qué puede designar; creo que porque es conocido, pues la ley permite un castigo equiparable.

Roto un miembro, prevalece el acuerdo entre las partes, en el que sin duda se incluyen penas sustitutorias. Y si el acuerdo no ha lugar, se aplicará el talión. ¿Se deduce de ahí que este consistía necesariamente en romper otro miembro al culpable? No lo creemos, pues en la referencia de esta palabra también caben penas sustitutorias no detalladas. Observemos que Festo lamenta que su antecesor Verrio Flaco no explique qué quiere decir la palabra talio. Y entiende que si no lo hace es porque era bien conocida, pues la ley permite la equiparación (permittit ... parem) del castigo. Si el talión romano consistiera en una pena materialmente igual al daño causado, Festo no se habría preguntado id quid significet. En cambio, su cuestión cobra sentido si está pensando en la referencia genérica que permite conmutar el tipo de pena, con tal que esta sea equiparable y proporcionada. 
De hecho, en el fragmento cuarto de la misma tabla se fija una cuantía de veinticinco ases por faltas y agresiones menores:

(4) Si INIVRIAM FAXSIT, VIGINTI QVINQUE POENAE SVNTO (8.4).

Si llega a cometer una falta, serán veinticinco ases de pena.

El riesgo que tiene la pena pecuniaria es que si se fija una cuantía y no se actualiza con arreglo a la devaluación de la moneda, la falta o delito puede salir prácticamente gratis, de manera que la infracción de la norma se presta al ridículo. Tal es el caso del insolente Lucio Veranio que en tiempos de Aulo Gelio (20.1.13) se permitía escarnecer a hombres libres, para que a continuación su esclavo les entregara la compensación prescrita de veinticinco ases.

Bastante más costosa resultaba la rotura de un brazo. Y en el fragmento tercero, transmitido por el jurista Paulo, además de la norma anterior, se recoge otra sobre daños físicos en que se impone también una pena pecuniaria:

(5) Manu fustiue si os fregit libero, CCC, (si) seruo, CL poenam subit sestertiorum (8.3).

Si con la mano o con un bastón ha fracturado un hueso a un hombre libre, sufre la pena de 300 sestercios, si a un esclavo, de 150.

Evidentemente, la compensación de membrum pro membro no daba lugar al abuso descrito por Gelio. La fractura de un miembro se castigaba con igual lesión desde la disposición 197 del código de Hammurabi («si un hombre ha fracturado el hueso de otro hombre, fracturarán su hueso»); asimismo en el Antiguo Testamento, como podrá verse en el texto del Levítico (24.19-20) citado en el capítulo final (24). El establecimiento de la sanción económica en época decenviral no es óbice para que también pudiera aplicarse el riguroso membrum pro membro, como parece desprenderse del siguiente fragmento de las Origines de Catón transmitido por Prisciano, en el que se dice expresamente que la fractura de un hueso, lo mismo que la rotura de un miembro, se castigaba con el talión ejecutado por el pariente más cercano:

(6) Si quis membrum rupit aut os fregit, talione proximus cognatus ulciscitur (Cato, Orig. 4.4).

$\mathrm{Si}$ alguien ha roto un miembro o fracturado un hueso, el pariente más próximo aplica la venganza del talión. 
Aunque, según pensaba Mommsen, Catón haría referencia al derecho de una ciudad latina, esa delegación de la venganza sería usual también en Roma ${ }^{1}$. Por otra parte, la discrepancia de esta norma con respecto a la distinción entre la rotura de un miembro y la fractura de un hueso, hecha en los fragmentos segundo y tercero de la tabla octava (supra 3 y 5), no ha dejado de crear dificultades interpretativas a la crítica $^{2}$. Ahora bien, de nuevo la contradicción es solo aparente, pues se toma talio en el sentido estricto de membrum pro membro, limitación que por su propio origen no tenía la palabra, según proponemos aquí. Al contrario, la sola introducción de talio representa una novedosa apertura referencial, gracias a la fuerza correlativa que aporta la base del indefinido talis.

\section{De la igualdad entre delito y pena a su equiparación}

La interpretación del contenido de tālio, -onis va unida sin duda a la cuestión del discutido origen de la palabra. Las dos propuestas principales, la de la procedencia céltica y la de la derivación del adjetivo tălis, han tenido aceptación diversa. En el diccionario de Walde - Hofmann ${ }^{3}$ se da mayor crédito a la hipótesis que relaciona la palabra con expresiones célticas que tienen el significado de 'paga' y 'pagar' y no consideran mejor solución la hipótesis que, basándose en el paralelo de duplio, -onis, presente asimismo en las XII Tablas, opta por entender tâliō como un derivado del adjetivo tālis. También Ernout - Meillet prefieren la base céltica tăl- y tratan de salvar la dificultad de la vocal breve alegando que la vocal larga de la palabra latina podría deberse a su acercamiento popular a tālis ${ }^{4}$. Con mejor criterio, De Vaan (2008, p. 605) rehúsa darle entrada particular e incluye el término jurídico directamente bajo la voz tâlis: "If tâliō is correctly interpreted as tâli-ōn, «compensation with the same» (Leumann 1977: 366), it is derived from tālis».

En contra de lo que parecen haber pensado los autores de los dos primeros diccionarios etimológicos citados, las ventajas de una solución dentro de la lengua latina son muy superiores a la de un préstamo céltico, improbable en

${ }^{1}$ Daremberg - Saglio 1969, s. u. talio.

${ }^{2}$ Chassignet 1986, p. 86: n. IV 4.1.

${ }^{3}$ LEW 1982, s. u. tāliō.

${ }^{4}$ DELL 2001, s. u. tāliō. No es diferente la breve explicación etimológica que se da en el Deli 2008, s. u. taglione, . 
un vocabulario técnico como el jurídico, poco abierto en principio a recibir elementos ajenos. Y es que tanto los argumentos morfológicos como los semánticos y sintácticos abogan por el origen interno ${ }^{5}$. En lo atinente a la formación sufijal, lo que dice Leumann a propósito de sustantivos verbales abstractos en -iōn-formados sobre adjetivos en -i- (communio, consortio) tiene pleno sentido para el tratado aquí: «tālio «Vergeltung mit Gleichem» (tālis, Korrelat zu quālis); danach dupl-io XII tab.» ${ }^{6}$. Acierta Leumann al señalar la correlación con qualis; pero por ello mismo ¿acaso es talio exactamente una compensación «mit Gleichem»y, como acepta De Vaan, «with the same»? Ahí ambos fuerzan el contenido de la base talis ${ }^{7}$.

La identidad de delito y pena era una cuestión debatida ya en la antigüedad. Aulo Gelio le dedica un amplio comentario en el último libro de las Noctes Atticae (XX 1.14-38). Por boca del filósofo Favorino se plantea si, además de la crueldad del castigo, es posible una ejecución justa del talión (executio iustae talionis) por la dificultad de lograr, rompiendo miembros corporales, una compensación pareja (rumpendi pariter membri aequilibrium) en las mismas condiciones de intencionalidad y sin cometer excesos que den lugar a una cadena recíproca de taliones (reciprocatio talionum). $\mathrm{Su}$ interlocutor, el jurisconsulto Sexto Cecilio, al contrario, reclama un juicio menos riguroso de leyes antiguas que han perdido vigencia y que han variado según las circunstancias políticas e históricas (14-22).

Este mismo más adelante (33-38) admite la disparidad del talión (quoniam talioni par non sit talio) y la dificultad de conseguir que sea una respuesta exacta (talionem parissimam); pero alaba su capacidad disuasoria, la posibi-

5 Según proponemos en otro trabajo (2017), de talis derivan también talea ('esqueje', hipercorrección de talia), término de la arboricultura, y el verbo taliare ( $>$ fr. tailler, it. tagliare, esp. tajar, tallar, pg. talhar, etc.). Ambos surgen con un sentido de 'proporcionalidad' análogo al de talio.

${ }^{6}$ Leumann 1977, § 324 A 2. Por su parte, Ernout - Meillet se confunden al asignar género masculino a talio, pues los diversos adjetivos que recibe la palabra son constantemente femeninos. Por tanto, cuando se menciona la palabra en latín, hemos de decir no el talio, sino la talio. El cambio de género es, evidentemente, románico, como ha ocurrido con el armazón, en vez de la armazón (< armatio, -onis). La masculinización románica puede llevar a entender el sustantivo como aumentativo, nota que viene a reforzar la idea de crueldad que comporta la práctica del membrum pro membro.

${ }^{7}$ Y asimismo otros. P. ej., en el Pauly - Wissowa (RE 1932, s. u. talio, col. 2069) se habla también de un castigo igual (dasselbe Übel). 
lidad de evitarlo mediante un pacto y finalmente el sometimiento al veredicto de un juez que puede acabar imponiendo una sanción pecuniaria:

(7) Nam si reus, qui depecisci noluerat, iudici talionem imperanti non parebat, aestimata lite iudex hominem pecuniae damnabat, atque ita, si reo et pactio grauis et acerba talio uisa fuerat, seueritas legis ad pecuniae multam redibat (Gell. XX 1.38).

Pues si el reo que no había querido llegar a un pacto, no se atenía al talión ordenado por el juez, una vez estimado el perjuicio, el juez lo condenaba a pagar una suma de dinero. Y así, si al reo le había parecido el pacto penoso y el talión cruel, el rigor de la ley venía a parar en una multa pecuniaria.

Por lo que hemos visto ya en la breve explicación de Festo (3), la palabra que mejor define la esencia del talión es el adjetivo par, pues la ley permite un castigo equiparable (parem uindictam). Sin embargo, Aulo Gelio insiste, tanto en la intervención del filósofo como en la del jurisconsulto, en que tal pena no era par, pariter, y mucho menos parissima respecto del daño inferido:

(8) Nam cui membrum ab alio ruptum est, si ipsi itidem rumpere per talionem uelit, quaero, an efficere possit rumpendi pariter membri aequilibrium? (Gell. XX 1.15).

Pues a quien otro le ha roto un miembro, si quisiera rompérselo él aplicando el talión del mismo modo, pregunto: ¿acaso podría lograr el equilibrio de romper el miembro en medida pareja?

(9) ... quoniam talioni par non sit talio... Verumst, mi Fauorine, talionem parissimam fieri dificillime (Gell. XX 1.33-34).

... ya que un talión no es como otro ... Es verdad, querido Favorino, que es muy difícil conseguir un talión absolutamente equitativo.

Gelio, en su defensa del talión, trata de destacar que esta norma no suponía la reproducción exacta de la ofensa o lesión inferida; lo que le lleva a negar por tres veces, como acabamos de ver, la «paridad» entre ambas. Ello parece contradecir la definición anterior de Festo (3), basada precisamente en el adjetivo par. Tal contradicción, más aparente que real, resulta de la relajación conceptual que permiten ciertos sinónimos. En efecto, par puede definirse como aequus, aequalis o aequabilis, según hace Cicerón: 
(10) par, quod in omnes aequabile est (Cic., Inu. II 68).

Par: lo que es igualable para todos.

No es extraño, pues, como observan Ernout - Meillet, que par vaya unido a menudo también a aequus, similis o idem ${ }^{8}$. Ahora bien, en nuestra opinión, par difiere de aequus y aequalis como similis se diferencia de idem. Y de acuerdo con esta distinción, la dificultad de aplicar el talión reside en reproducir un castigo que sea exactamente igual (aequus, aequalis) o idéntico (idem) al daño causado; pero puede ser perfectamente equiparable (par) o similar (similis). Y esa es condición suficiente para ser equitativo y justo9.

En el siguiente texto de Quintiliano se ponen de manifiesto, en nuestra opinión, las dos condiciones primordiales del talión: su equiparación e indeterminación. Se confirma, en efecto, la idea de que par ('equiparable, equitativo') es el adjetivo más adecuado para definir el talión. Pero además la expresión et talia que deja abierta una serie sinonímica, como si fuera un et cetera, revela el valor indefinido de la base de talio, de manera que la referencia de este sustantivo, siendo en todo caso equiparable, no es en principio determinada

(11) Iustum omne continetur natura uel constitutione; natura, quod fit secundum cuiusque rei dignitatem. Hinc sunt pietas, fides, continentia et talia. Adiciunt id, quod sit par. Verum id non temere intuendum est: nam et uis contra uim et talio nihil habent aduersum eum, qui prior fecit, iniusti; et non, quoniam res pares sunt, etiam id est iustum, quod antecessit (Quint., Inst. VII 4.6).

Todo lo justo se clasifica en natural o convencional; es natural lo que se hace según la dignidad de cada cosa. De este tipo son la piedad, la buena fe, la

${ }^{8}$ DELL 2001, s. u. par.

${ }^{9}$ La laxitud en la aplicación de los conceptos de igualdad y semejanza en la distinción de los sinónimos, definidos por los rétores y gramáticos romanos como uerba idem significantia (Quint., Inst. IX 3.45-46), ha metido a los estudiosos modernos en una polémica aporía. Por creer que la expresión latina quiere decir «palabras que significan lo mismo», hay quienes han terminado concluyendo que los sinónimos no existen y solo hay parasinónimos. En realidad, la definición de Quintiliano solo quiere decir «palabras que designan lo mismo», esto es, palabras que en contexto pueden tener la misma referencia, como los cuatro verbos que sirven de ejemplo a la definición anterior: abiit, excessit, erupit, euasit («se ha ido, se ha marchado, ha salido, ha escapado»). Los cuatro, referidos a la huida de Catilina, designan el mismo hecho, pero tienen, evidentemente, distintos significados, significados que no pasan de ser semejantes y, por tanto, sinónimos (García-Hernández 1997, pp. 15-16; 2012, pp. 59-63). 
continencia y otras tales. Añaden también lo que puede ser equiparable. Pero esto no se ha de considerar precipitadamente; pues tanto la violencia contra la violencia como el talión no tienen nada de injusto contra el que actuó primero; y puesto que las acciones son equiparables, no por ello es también justa la que precedió.

He ahí, pues, cómo las cosas equiparables (pares) son tales (talia) y cómo el talión es 'tal' en cuanto que es equiparable a la acción agresora que lo precedió; pero, a diferencia de esta, no deja de ser una acción equitativa y, en cuanto que se consideraba justa, se estableció como norma. Nueve siglos después de la fijación de las XII Tablas, el poeta Draconcio, en su condición de jurisconsulto, insiste en esa equiparación entre pena y delito:

(12) Si par sententia damnet, quos par culpa tenet (Drac., Laud. dei III 755). Si una sentencia equitativa condena a quienes tienen una culpa comparable.

Pues bien, ese ideal de equidad en la imposición de la pena había sido preconizado, según venimos sosteniendo, desde la ley del talión por la propia expresión talio y el valor correlativo de su base etimológica talis.

\section{La base correlativa de la talio}

Por talión suele entenderse una norma cruenta y arcaica, cuya práctica se remonta sin duda mucho más allá de la época decenviral. En esa primera fase, según ocurre también en otros derechos primitivos, debía de exigirse con mayor rigor el membrum pro membro como castigo del malhechor. Aun sin excluir este, la introducción en las XII Tablas del sustantivo abstracto talio, -onis, formado sobre el adjetivo tālis, supuso consagrar el cambio de la pena violenta, como réplica exacta del daño recibido, por otra equiparable. Eso es lo que permite entender la definición asidua de tâlio por el adjetivo par, según hemos visto en el capítulo anterior, y es la conclusión a la que cabe llegar desde la base del indefinido talis como correlativo de qualis. El talión como reacción es talis y lo es como respuesta a una acción agresora que es qualis. Es la cualidad de esta la que determina la paridad de aquella, como si dijéramos cual es el delito tal será el castigo.

Por ello, el talión no solo es una norma arcaica que admite castigos sustitutorios del membrum pro membro, sino que su nombre surge de una estructura lingüística antigua que se establece entre una forma de base relativa 
(qualis) y otra correlativa (talis), según se ve en el ejemplo siguiente en el que Cicerón expresa cierto pensamiento platónico:

(13) ... quales in re publica principes essent, tales reliquos solere esse ciues (Cic., Fam. I 9.12).

... que, cuales fueran los ciudadanos principales en el estado, tales solían ser los demás.

Esta estructura bimembre, heredada del indoeuropeo y bien conservada en los lenguajes técnicos, como el jurídico y el administrativo, se manifiesta en formulaciones pronominales y conjuntivas diversas, a menudo con sentido proverbial $^{10}$ :

(14) qui ... is: Cui prodest scelus, is fecit (Sen., Med. 500-501).

El que sale beneficiado cometió el delito.

(15) qualis ... talis: Qualis dominus, talis et seruus (Petron. 58.3). A tal dueño tal siervo.

(16) quot ... tot: Quot homines, tot sententiae (Ter., Phorm. 454).

Tantos pareceres como personas.

(17) $u b i$... ibi: Vbi amici, ibidem opes (Plaut., Truc. 885).

Donde hay amigos, alli está la riqueza.

(18) si ... tum: Si malas imitabo, tum tu pretium pro noxa dabis (Liu. Andr., Trag. 1).

Si tomo por modelo a unas cobardes, entonces tú pagarás el coste del error.

Cometida una falta o producido un delito, surge la pregunta: qualis poena? Sin concretar el castigo, no hay respuesta más adecuada que la correlativa: quale scelus talis poena. Ese es el orden sintáctico antiguo: primero el relativo de cualidad y a continuación el correlativo. La disposición en que el elemento relativo (qualis) precede al correlativo (talis) no dejó de invertirse en el curso histórico de la lengua latina, sobre todo en los niveles expresivos próximos a la lengua oral: talis poena quale scelus. Este nuevo orden se

\footnotetext{
${ }^{10}$ Haudry 1973, p. 153 ss.; Panchón 1982, p. 9, 15; Sánchez Salor 1973, p. 35 ss.; Orlandini y Poccetti 2012, pp. 33-35; Tosi 2000, §§ 809, 968, 969, 1112, 1318, 1729, 1445.
} 
consolidará en las lenguas románicas, según vemos en los textos siguientes y sus traducciones:

(19) Nec meu' seruos numquam tale fecit quale tu mihi (Plaut., Merc. 1027). Ni un siervo mío ha hecho jamás una acción tal cual la tuya por mí.

(20) Litteras tuas uehementer exspecto, et quidem talis qualis maxime opto (Cic., Fam. X 22.2).

Espero con vehemencia tu carta y sin duda tal cual la deseo en gran manera.

No obstante, en romance se mantiene sin dificultad el orden antiguo, si se elimina el elemento relativo en beneficio de la repetición del correlativo, como marcador único:

A tal delito tal castigo.

De tal padre tal hijo; de tal palo tal astilla.

Fr. tel père, tel fils.

It. tale il padre, tale il figlio; tale il padrone, tale lo schiavo.

Se trata del orden lógico de sucesión por el que el delito antecede la pena impuesta o el padre precede como modelo al hijo, etc. Y dentro de ese orden el relativo o cualquiera de sus variantes (qualis, si ...) introduce el antecedente y el correlativo (talis, tum ...) el consiguiente:

(21) si antissent delicta, poenae sequerentur (Tac., Ann. III 69).

Si precediesen los delitos, seguirían las penas.

Es asimismo el orden que corresponde a la estructura informativa del tema como soporte conocido y del rema como aporte novedoso ${ }^{11}$. El delito, pues, da la medida de la pena en el plano judicial, como si ambos se equilibraran en la balanza de la justicia: el primero indicado por qualis y el segundo propuesto como talis. Esta imagen del emblema de la justicia puede dar una fiel idea de la variación referencial de talio como pena equiparable al delito.

El sustantivo talio, pues, lleva en sí desde su origen la fuerza estructural de la correlación bimembre que hemos explicitado de forma ideal en quale scelus, talis poena («cual el daño, tal la pena»). Es más, nada de particular tendría que el adjetivo talis, asociado a un sustantivo como damnatio (talis damnatio «tal

\footnotetext{
${ }^{11}$ Fruyt 2013, pp. 129-132.
} 
la condena»), tomara de él el sufijo de acción para crear el nuevo sustantivo talio. Si volvemos a la formulación decenviral (Si membrum rup $<s>$ it ... talio esto), observamos que lleva en sí el cruce de dos estructuras correlativas: la de si ... (tum) y la de (qualis) ... talis. Dada la recurrencia de la prótasis condicional en el estilo legal, parece obvio que haya ocurrido así. Por lo demás, la segunda partícula de la correlación condicional si ... tum ... (si ... entonces ...) contiene el mismo radical que talis, de manera que su sustitución es obvia.

Cabe añadir que las correlaciones cualitativas son normales en la lengua jurídica, de forma explícita en esta sentencia sobre el objeto en litigio:

(22) Quale est, cum petitur, tale dari debet (Papin., Dig. XXII 1.2).

Cual es, cuando se reclama, tal debe darse.

Y de forma implícita puede verse en la siguiente consideración de Tertuliano sobre la calidad de los juzgados y la sentencia que merecen de quien los condena. No es casualidad que en el lugar en que podía aparecer el correlativo tales, que no deja de tener origen deíctico ${ }^{12}$ antes que fórico, aparezca el verbo demonstrat:

(23) Quales simus, damnator ipse demonstrat (Tert., Nat. II 7).

Cuáles somos, (tales) lo demuestra el propio que condena.

Comenzamos nuestra exposición señalando el detalle de miembro por miembro en el talión que se prescribe en el Exodo bíblico (2) y antes de concluirla aducimos un texto del Levítico, en el que se pone de manifiesto su estructura correlativa:

(24) Qui inrogauerit maculam cuilibet ciuium suorum sicut fecit fiet ei fracturam pro fractura oculum pro oculo dentem pro dente restituet qualem inflixerit maculam talem sustinere cogetur (Vulg., Leu. 24.19-20).

Al que haya inferido un golpe a cualquiera de sus conciudadanos se le hará como él ha hecho: pagará fractura por fractura, ojo por ojo, diente por diente; será obligado a recibir una lesión tal cual la que ha infligido.

Si se compara el texto latino con el griego de Septuaginta y con el hebreo, se comprueba que en estos hay correlación adverbial, mientras en el latino es

${ }^{12}$ IEW 1086, s.v. to-, $t \bar{a}$. 
adjetiva. En cambio, en un texto análogo del código de Hammurabi no hay correlación ${ }^{13}$. Los dos adjetivos del texto latino (qualem ... talem) determinan el mismo sustantivo maculam, que representa el efecto producido por el golpe o lesión. Por tanto, se está todavía en la fase primitiva del talión, en que la pena es la misma que el daño causado. En cambio, el sustantivo talio, como innovación de las XII Tablas, abre la puerta a penas distintas que sean equiparables. Por más que la palabra talio no aparezca, detrás de la correlación latina qualem ... talem se adivina el pensamiento romano de Jerónimo y la conciencia etimológica que tiene del sustantivo ${ }^{14}$.

Los juristas romanos eran conscientes de que el rigor extremo engendra mayores agravios (summum ius summa iniuria). Desde la primera gran fuente jurídica se observa la tendencia a huir de la crueldad extrema sin llegar a la benignidad evangélica. El agredido no tiene por qué pagar en la misma moneda al agresor, sacándole ojo por ojo, diente por diente, ni tampoco ofrecerle la otra mejilla, para que repita la agresión (Vulg., Matth. 5.38-39). Hay soluciones más civilizadas como la que promueve la auténtica ley romana del talión que frente a la igualdad en la reacción viene a imponer, gracias a una certera creación léxica, el criterio de equidad, el de una pena equiparable y proporcional al daño inferido.

${ }^{13} \mathrm{He}$ aquí, a este propósito, los datos que nos ha suministrado nuestro colega Rafael

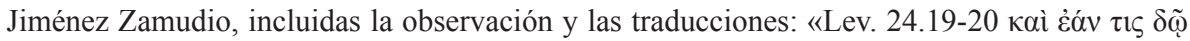

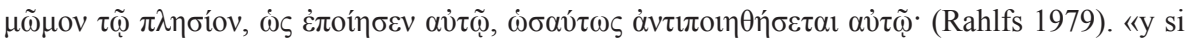
alguien hace un reproche a un conciudadano, tal como a él hizo, de igual modo se le hará». Es curioso que no se hable de «lesión» sino de «reproche, censura» que es lo que significa $\mu \tilde{\omega} \mu$ os. De hecho Jerónimo lo traduce por maculam. Posiblemente el griego haya querido emplear una palabra que conserva una clara homofonía con el hebreo mum cuyo significado cubre los valores de «censura» y «lesión».

La transliteración del texto hebreo es: weish ki-yitten mum ba'mito ka'aser 'asah ken ye'aseh lo (Elliger y Rudolph 1966/77). «Y si un hombre produce una lesión a su conciudadano, como ha hecho, así se hará con él».

Las disposiciones 196 y 197 del código de Hammurabi (Hammurapi), escrito en paleobabilonio, dicen (Borger 1979):

196) shumma awīlum ìn mār awìlim uhtappid ìnshu uhappadū

«Si un hombre ha reventado el ojo del hijo de otro hombre, reventarán su ojo»

197) shumma esemti awīlim ishtebir esemtashu ishebbirū

«Si un hombre ha fracturado el hueso de otro hombre, fracturarán su hueso».

${ }^{14}$ Es de notar que la formulación similar del ojo por ojo en Deut. 19.21 va precedida también del indefinido talis referido al delito (ut ... nequaquam talia audeant facere: «para que ... en vano se atrevan a cometer tales acciones»). 
Confirmado el origen correlativo del término jurídico talio, cabe decir de él que, aunque surgió en una época arcaica, desde el punto de vista jurídico y lingüístico es realmente innovador. Pese a su base adjetiva, es un sustantivo de acción como lo es damnatio en la designación de la condena. Y en lo atinente a su contenido jurídico, supone franquear la barrera del membrum pro membro relativizando la naturaleza de la pena respecto del delito, pero sin perder su equiparación y sin romper el equilibrio que exigía la justa compensación. La imagen de la balanza (lat. libra bilanx), en cuyos platillos (lat. lances) se coloca el delito como quālis y la pena como tālis, en busca del deseado aequilibrium, parece haber estado muy presente en tal correlación.

La base indefinida talis transmite a su derivado talio la función fórica característica de un correlativo. Su referencia, necesariamente elástica, permite no solo variar la pena, siempre que sea equiparable al delito, sino incluso aplicar la palabra a la compensación por un beneficio, según el elocuente testimonio de Isidoro de Sevilla:

(25) Talio est similitudo uindictae, ut taliter quis patiatur $u t$ fecit. Hoc enim et natura et lege institutum, ut 'laedentem similis uindicta sequatur'. Vnde et illud est legis [Matth. 5.38]: 'Oculum pro oculo, dentem pro dente'. Talio autem non solum ad iniuriam referendam, sed etiam pro beneficio reddendo ponitur. Est enim comunis sermo et iniuriae et beneficientiae (Orig. V 27.24). El talión es la semejanza de castigo, por la que alguien sufre un daño tal como el que ha causado. Esto está establecido, en efecto, por naturaleza y por ley, para imponer un castigo semejante al que ha producido una lesión. De ahí también viene lo de la ley: «ojo por ojo, diente por diente». Pero el talión se establece no solo para devolver una ofensa, sino también para recompensar un beneficio. Es, pues, expresión común del agravio y de la buena acción.

El Hispalense, al final de la Antigüedad, mantiene viva la conciencia etimológica de talio, puesto que lo explica por medio de taliter en correlación con el ut comparativo; en consecuencia, no habla de castigo igual, sino semejante (similitudo, similis). A continuación cae en la contradicción de insertar el ojo por ojo bíblico, con lo que casi arruina su argumento. Pero supera con creces su error dejando constancia del doble vuelo de talio, como compensación negativa por un agravio o positiva por un beneficio. Todo ello viene a confirmar la presencia de la base indefinida de talis en el sustantivo. No puede quedar, pues, más claro que talio representa la superación de la igualdad radical de la pena respecto del delito, mediante su paridad y equiparación. 


\section{Conclusión}

Proporcionalidad o desproporción de las penas han sido siempre tema de debate, un debate que se renueva cada vez que se plantea la reforma de un código penal. Conocido y visto el delito, la cuestión es qualis poena? Y la respuesta obvia: quale scelus, talis poena. La creación técnica de talio, como derivado de talis, tuvo la virtud de establecer el principio de proporcionalidad, con independencia de la concreción de la pena. Esa es su gran novedad: situar la pena como entidad equiparable en el orden teórico y abstracto de un sistema correlativo. Y así, desde su base indefinida la talio ofrecía un marco conceptual y referencial abierto que permitía evolucionar, de la pena rigurosamente igual al daño inferido, a una pena sustitutoria más civilizada, sin renunciar a la equiparación con el delito.

Por su datación antigua, talio podrá considerarse un vocablo arcaico entre los muchos que contienen los fragmentos de las XII Tablas; a ello no ha dejado de contribuir su identificación posterior con el ojo por ojo. Como norma arcaica, se le ha endosado el sentido estricto de membrum pro membro, característico del texto bíblico. Puede decirse que en principio la justicia, al menos en el ámbito privado, se administraba en especie (brazo por brazo, ojo por ojo), como se comerciaba en especie (una vaca por cinco ovejas, pongamos por caso). El prototipo de especie mercantil en el mundo romano fueron los animales domésticos, el ganado: lat. pecu. Tal es el sentido etimológico del derivado pecunia antes de convertirse en dinero contante y sonante y de emplearse como sustituto pecuniario en la transacción comercial y también en el arreglo judicial ${ }^{15}$.

Ahora bien, mientras pecunia no dejó de llevar consigo el referente del comercio pecuario, talio superó desde el propio nombre, por su origen gramatical e indefinido, la barrera concreta del membrum pro membro para situarse en el nivel abstracto en que tenían cabida penas equiparables. Así pues, el análisis lingüístico permite reconocer en talio, mejor que un arcaísmo, un antiguo neologismo de concepto genérico y referencia amplia que vino a representar un gran avance en la humanización de la norma consuetudinaria del ojo por ojo. Para comprender el espíritu innovador de la ley del talión, histó-

${ }^{15}$ El abstracto pecunia, que se atestigua desde los primeros textos con el valor crematístico de 'dinero', debió de representar en principio la «richesse mobilière» (Benveniste 1969, pp. 52-54). 
ricamente trastocado por el continuo repique bíblico, es ineludible atenerse a su letra: a lo que significa y supone talio como creación léxica. Y su letra, lejos de dictar un riguroso miembro por miembro, mantenía el espíritu abierto del indefinido talis, correlativo de qualis que calificaba el delito.

\section{BibLIOGRAFÍA}

Benveniste, É. 1969: Le vocabulaire des institutions indo-européenes. 1. Économie, parenté, société, París.

Borger, R. 1979²: Babylonisch-Assyrische Lesestücke, Roma.

Chassignet, M. 1986: Caton, Les Origines, París.

Daremberg, Ch. y E. Saglio, E. 1969: Dictionnaire des antiquités grecques et romaines, Graz.

DELI 2008: Cortelazzo, M. y Zolli, P., Dizionario etimologico della lingua italiana, Bolonia.

DELL 2001: Ernout, A. y Meillet, A., Dictionnaire étymologique de la langue latine. Histoire des mots, París.

De Vaan, M. 2008: Etymological Dictionary of Latin and the other Italic Languages, Leiden.

Elliger, K. y Rudolph, W. (eds.) 1966/774: Biblia Hebraica Stuttgartensia, Stuttgart.

Fruyt, M. 2013: «La corrélation en latin: statut et évolution», en Inkova, O. y Hadermann, P. (eds.), La Corrélation. Aspects syntaxiques et sémantiques, Ginebra, pp. 109-146.

García-Hernández, B. 1997: «Sinonimia y diferencia de significado», RSEL 27, pp. $1-31$

García-Hernández, B. 2012: «En torno a la semántica coseriana. Sinonimia y sistema clasemático», en Martínez del Castillo, J. (coord.), Eugenio Coseriu (1921-2002) en los comienzos del siglo XXI, Málaga, pp. 57-72.

García-Hernández, B. 2017: «Lexicalización en los indefinidos latinos. Tãlis como base léxica», Études de linguistique latine 2. Pallas 103, pp. 211-218.

Haudry, J. 1973: «Parataxe, hypotaxe et correlation dans la phrase latine», BSL 68, pp. 147-186.

IEW 1959: Pokorny, J. Indogermanisches etymologisches Wörterbuch, Berna.

Leumann, M. 1977: Lateinische Laut- und Formenlehre, Múnich.

LEW 1982: Walde, A. y J. B. Hofmann, Lateinisches etymologisches Wörterbuch, I-II, Heidelberg.

Orlandini, A. y Poccetti, P. 2012: «L'évolution de l'ancien diptyque indo-européen ${ }^{*} k^{\mathrm{w}} O-\ldots{ }^{*} t o-$ du latin aux langues romanes», en Christol A. y Spevak, O. (éds.), Les evolutions du latin, París, pp. 27-44. 
Panchón Cabañeros, F. 1982: La frase correlativa en latín arcaico, Universidad de Salamanca, Tesis doctoral inédita.

Rahlfs, A. 1979: Septuaginta, Stuttgart.

RE 1932: Paulys Realencyclopädie der classischen Altertumswissenschaft, Bd. IV A 2, Stuttgart.

Sánchez Salor, E. 1984: Sintaxis Latina: la correlación, Cáceres.

Tosi, R. 2000: Dizionario delle sentenze latine e greche, Milán.

Fecha de recepción de la primera version del artículo: 23/12/2016

Fecha de aceptación: 11/02/2017

Fecha de recepción de la version definitiva: 15/02/2017 